\title{
Where Do We Stand on Locating the Self?
}

\author{
Jakub Limanowski ${ }^{1}$, Heiko Hecht ${ }^{2}$ \\ ${ }^{1}$ Faculty of Psychology, Ruprecht-Karls-Universität Heidelberg, Heidelberg, Germany; \\ ${ }^{2}$ Faculty of Psychology, Johannes Gutenberg-Universität Mainz, Mainz, Germany. \\ Email: jakub.limanowski@urz.uni-heidelberg.de \\ Received February $8^{\text {th }}, 2011$; revised March $16^{\text {th }}, 2011$; accepted April 20 $0^{\text {th }}, 2011$.
}

\begin{abstract}
The subjective location of the Self in the body is a traditionally problematic question, and it can only be addressed from the first-person perspective. However, this does not preclude an empirical approach to the question. In the present study, we examined whether a large sample of participants would be willing and able to determine the perceived location of their Self. The main goal was to assess current beliefs about the nature of the Self and its assumed relation to specific bodily organs. Eighty-seven participants indicated the center of their Self by placing crosshairs on human silhouettes and abstract, non-human silhouettes with varying anatomy. Results suggest a dominant role of the brain and the heart for Self-location in humans, but only of the brain for Self-location in abstract creatures. Moreover, most people seem to believe there is one single point inside the human body where their Self is located.
\end{abstract}

Keywords: The Self, Self-Location, Egocenter, First-Person Perspective, Self-Report

\section{Introduction}

Trying to understand the relation between the Self and the body is a task that has proven to be traditionally problematic and has bothered philosophers since Aristotle and Descartes (cf. James, 1890; Merleau-Ponty, 1962; Nagel, 1971; Clark, 1999). A great part of the difficulty of this question may arise from the fact that the (healthy) body and the Self are experienced as an elementary unity in our everyday lives, with the sense of the body being fundamentally linked to the sense of self (Damasio, 1999; Gallagher, 2005; Blanke \& Metzinger, 2008). It is not surprising, then, that among the first questions addressed by early scientists was the location of the Self in the physical body. Throughout history, distinct bodily organs, like the heart (Aristotle) or the pineal gland (Descartes) have been proposed as the "seat" of the Self (or soul). Many modern philosophers, too, locate the Self in a specific place inside the human body, preferably the brain. But not only in philosophy do such localization attempts abound: in common parlance, one can be "beside oneself" or "out of one's mind", and when we talk about ourselves we use metaphors involving perspective, suggesting that we intuitively place our Self in one specific location.

Despite the apparent salience of the problem, it was not until the early 1920s that modern researchers have made first serious attempts to empirically locate the Self. Not surprisingly, the majority of early theories about the location of the Self stem from visual perception research. Hering's projective geometry (Hering, 1942) states that an observer perceives a scene as if he was viewing it from a single cyclopean aperture between the two eyes. Although the generalizability of Hering's projective geometry has been criticized (Helmholtz, 1962; Erkelens \& Ee, 2002), various studies (e.g. Ono \& Angus, 1974; Mapp \& Ono, 1999) support the idea and functionality of such a single vantage point, which has been located in the median plane on the Vieth-Müller circle (Hering, 1942), or behind the bridge of the nose (Claparède, 1925; Roelofs, 1959; Merker, 2007). This point has since been called the cyclopean eye (Helmholtz, 1962; Hofmann, 1926; Mapp \& Ono, 1999) or the egocenter (Roelofs, 1959; Howard \& Templeton, 1966; Merker, 2007).

Recent research supports the idea of an egocentered consciousness. In a study by Bertossi, Besa, Ferrari, and Ferri (2008), most participants located the "I-that-perceives" in the head midway behind the eyes. Neelon, Brungart, and Simpson (2004) found approximate concordance of the locations of the visual and auditory egocenters in normally sighted participants. Consistently, Sukeyima, Nakamizo, and Ono (2008) reported a correspondence of the (assumed) visual and auditory egocenter, and attempts have been made to locate the kinesthetic egocenter (Shimono, Higashiyama, \& Tam, 2001).

However, it might be argued that geometrical analysis of sensory input leaves out an important aspect of the first-person perspective, namely its subjective character. Pioneer studies conducted by Claparède (1925), Hofmann (1926), and Funaishi (1926) attempted to address the subjective experience of being an observer in one specific location. Unfortunately, all of these early studies were only introspections of the researchers themselves - a fact that led to divergent results, and to a general reluctance of researchers to occupy themselves with such an elusive topic.

Perhaps for this reason, until recently the question of the location of the Self has not been deemed worthy of investigation. There are two potential show-stoppers for an empirical investigation of the egocenter, one being the a priori futility of the endeavor, and the other one being a lack of empirical methods or operationalizations. However, from a philosophical point of view, the quest to localize the Self cannot be easily dismissed, at least not unanimously so. Analytical philosophy focuses increasingly on the "self-centeredness" of consciousness (Metzinger, 2004; Blanke \& Metzinger, 2008) and maintains, for instance, that perception places the observer at the center of the world (Roelofs, 1959; Howard \& Templeton, 1966; Brewer, 1992) or of an "egosphere", a coordinate system onto which our 
senses project the world (Albus, 1991; Merker, 2007).

The self-centeredness of human consciousness manifests itself in action and space perception (Amir \& Kugelmass, 1959; Grossberg, Guenther, Bullock, \& Greve, 1993; Cutting, 1997; Metzger, 2001; Merker, 2007), and artificial intelligence design has long recognized its importance (Albus, 1991). Moreover, pathological disorders and illusions like out-of-body-experiences (Blanke \& Metzinger, 2008) are often very closely linked to disruptions in the first-person perspective of human consciousness. Therefore we believe that locating the Self is a crucial task that could produce manifold benefits. However, attempts to locate the egocenter are still lacking solid empirical data, both regarding the general feasibility and particular shape.

\section{The Goal of This Study}

In the present study, we assessed to what extent and where precisely present-day participants are willing and able to locate their Self by conducting a large-scale internet-based survey. The main goal of this study was not to find the true location of the Self, but rather to gather data about current beliefs about the nature of the Self, above all including the question about its localizability and its assumed relation to specific bodily organs. To our knowledge, such a large-scale survey has not yet been conducted.

We believe that an operationalization of the Self-building upon the historical concept of the egocenter-is possible even when abstaining from case-based introspection as the method of choice. People's claims and beliefs can be of extreme value when treated correctly (Dennett, 2003), and this is especially true for a question like the perceived location of the Self, which is defined by its subjective, first-person character. Thus, we see no principled reason against empirically determining the perceived location of the Self.

The current study had two main goals. First, we sought to accumulate data from a large sample, in contrast to the classic studies that typically relied on one single observer. Second, we wanted to examine whether participants' judgments would correspond to a world-view which focuses increasingly on the brain (and not, for example, the heart) as being the "central organ" responsible for establishing the Self. Furthermore, it was not clear whether participants would be at all able and willing to comply, as such a task requires both detailed observations and a specific belief about the nature of the Self.

In the first part of the study, participants had to locate the Self graphically by placing crosshairs on a human silhouette from three different perspectives. To account for the origins of research on the location of the Self, which have been inspired by vision research, we decided to introduce a further conceptual specification of the Self in terms of a phenomenal Self - meaning the perceived center of phenomenal experience - to half of the participants. This differentiation allows to compare beliefs about the nature of the Self and to determine whether they are robust or subject to change based on a simple definition.

In the second part of the study, we replaced the human silhouette with abstract, non-human rectangular silhouettes, which now additionally contained human-like organs in anatomically varying positions ${ }^{1}$. The purpose of this part was to examine

${ }^{1}$ This was not done in the first part to avoid biasing the participants' Selflocations by displaying bodily organs inside the human silhouette. whether a location of the Self would still be assigned to the abstract silhouettes and if so, whether it correlated with the position of specific organs. Choosing abstract silhouettes for this part was based on the assumption that a human silhouette with varying positions of bodily organs would be perceived as unnatural and disturbing, and would thus interfere with the task at hand.

\section{Part 1: Locating the Self on a Human Silhouette}

\section{Method}

Eighty-seven subjects ( 56 female; mean age $=26.5$ years; range $=16-59$ ) volunteered to participate in the study online ${ }^{2}$ (runtime August-September 2009). All programs were written and run in Adobe Flash. Three perspectives of a human silhouette were used for the task (front view, $135 \times 457$ pixels; side view $73 \times 457$ pixels; top view, $128 \times 64$ pixels).

Participants first completed a questionnaire on demographic data, as well as a self-evaluation of their abilities in the natural sciences, the humanities, and spatial orientation. After this, participants were randomly assigned to one of two conditions:

1) The Self: no further instructions on what was meant when referring to the "Self".

2) The phenomenal Self: a short introductory text was given explaining the Self with reference to the center of phenomenal experience.

Participants were advised to tag a point on each of the three silhouettes that they thought would best describe the location of their (phenomenal) Self. After participants had read the instructtions, the mouse cursor was replaced with crosshairs. Mouse clicks could be corrected, and participants had to indicate how well they thought their final judgment described the location of their (phenomenal) Self on a four-point Likert scale ( $1=$ "very poorly" to 4 = "very well"). After completing the Self-location judgments, participants were asked whether they thought there existed a single point at which the (phenomenal) Self was experienced, and whether certain bodily organs were of special importance to this point (open format question).

\section{Results}

Of all participants, only $8.42 \%$ aborted the study before the first Self-location judgments could be collected. Another $8.21 \%$ of participants did not complete both parts of the experiment. Incomplete datasets were excluded from the analyses.

Figure 1 shows the distribution of the Self-location judgments (SLJ) produced by all participants. A cluster analysis found two clusters (and one outlier) after the first iteration. As shown in Figure 1, the means of the two clusters correspond well to the positions of the brain and the heart in the human body. The conditions Self vs. phenomenal Self did not differ significantly in their SLJ distributions (oneway ANOVAs, all ps > .21), or the certainty about their judgments (oneway ANOVAs, all $p \mathrm{~s}>.39$ ). However, slightly more participants in the "phenomenal Self" condition located the Self in the upper cluster (the brain), than in the "Self" condition $(66.7 \%$ vs. $54.2 \%$, front view).

Most participants agreed that there existed one single point at

\footnotetext{
${ }^{2}$ The web-based experiment was advertised on various German university
} websites. 


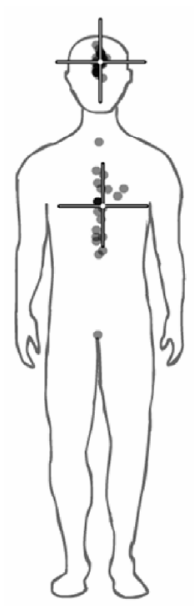

Self

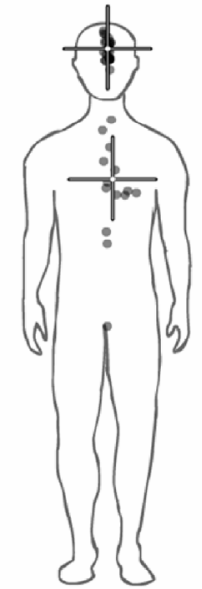

phenomenal Self

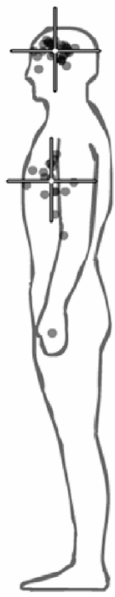

Self

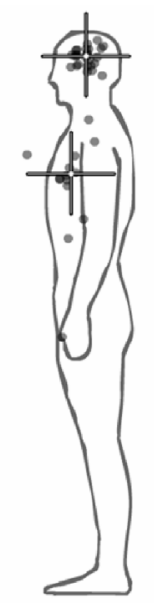

phenomenal Self
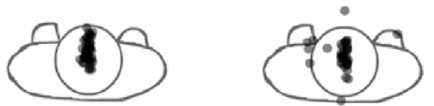

Self

phenomenal Self

Figure 1.

Self-location judgment (SLJ) distributions overlaid onto the human silhouette for both instruction conditions (Self vs. phenomenal Self). Each dot represents one participant's SLJ tag. Crosshairs mark the two cluster centers that were identified.

which the (phenomenal) Self was experienced (72.3\% "yes"). Among the reported important bodily organs, the brain (34 times) and the heart (18 times) were mentioned most frequently, followed by the stomach and the eyes. Again, there was no significant difference between conditions.

Overall, participants judged their own abilities in the natural sciences, the humanities, and spatial orientation as good. Average ratings were: $3.12(0.58)$ for ability in the natural sciences; $2.9(0.65)$ for ability in the humanities; and $2.79(0.78)$ for spatial orientation ability (means with standard deviation on a four-point Likert scale ranging from $1=$ "very poor" to $4=$ "very good"). Participants also thought their self-location judgments described the location of their Self in a veridical way: means for all perspectives were $>3$ (on a four-point Likert scale from 1 = "very poorly" to 4 = "very well"). There were no significant differences in the certainty about the SLJs or the judgments of one's own abilities between participants who located the (phenomenal) Self in the upper cluster compared with participants who located it in the lower cluster (oneway ANOVAs, all $p s>.32$ ).

\section{Part 2: Locating the Self on Non-Human Silhouettes}

\section{Method}

Eleven rectangular silhouettes $(247 \times 494$ pixels; front view only) were displayed subsequently in a different random order for each participant. Each rectangle consisted of a rectangular "body" with two eyes and ears ${ }^{3}$, a heart, and a brain. The vertical positions of these organs (top-center-bottom) varied among the rectangles. A fully crossed design covering all possible combinations of the organs would have been prohibitively long and repetitive. Thus, we chose 11 pertinent combinations, which contained each feature at least once in each of the three positions.

\footnotetext{
${ }^{3}$ To maintain a level of abstraction, we chose to only display the important sensory organs eyes and ears.
}

A short introductory text described the "rectangles" as creatures very similar to humans. As with the human models in part 1, participants had to tag a point that best described the location of the Self on each of the rectangles. Neither of the groups received further information about which Self was meant in this part of the experiment.

After completing the SLJS for the rectangles, participants were asked whether they thought there existed a single point in the rectangles' body, at which subjective experience is strongest. The same question was then posed about the human body. If answering "yes", participants were asked whether they thought the location of this point depended on the position of the sensory organs, the brain, the heart, or other variables. Participants were given the opportunity to add questions or comments regarding the study.

\section{Results}

A total of $8.21 \%$ of participants dropped out of this part of the experiment. Incomplete datasets were excluded from the analyses. Figure 2 shows cluster plots of the SLJs averaged across both conditions (with and without prior definition of the phenomenal Self in part 1) for each of the eleven rectangles. The conditions Self vs. phenomenal Self did not differ significantly in their SLJ distributions $(F(1,818)=1.21, p=.27)$ or their certainty about the judgments $(F(1,818)=0.32, p=.57)$.

The distribution of the SLJs was strongly influenced by the relative position of the rectangles' organs: vertical standard deviation of the SLJ tags increased with greater mean distance between the organs, Pearson's $r=.96 ; p<.001$ and $r=.89 ; p$ $<.001$ for the two conditions. Correspondingly, the certainty about the judgment was lower for rectangles with greater mean distance between their organs, Pearson's $r=-.68 ; p<.021$ and $r=-.67 ; p<.024$, and the only clear cluster was found for the rectangle where ears, eyes, heart, and brain were all located at the center.

Partial correlations showed no significant effect of the position of the rectangles' heart on the location of the SLJs. However, the vertical position of the rectangles' brain correlated 


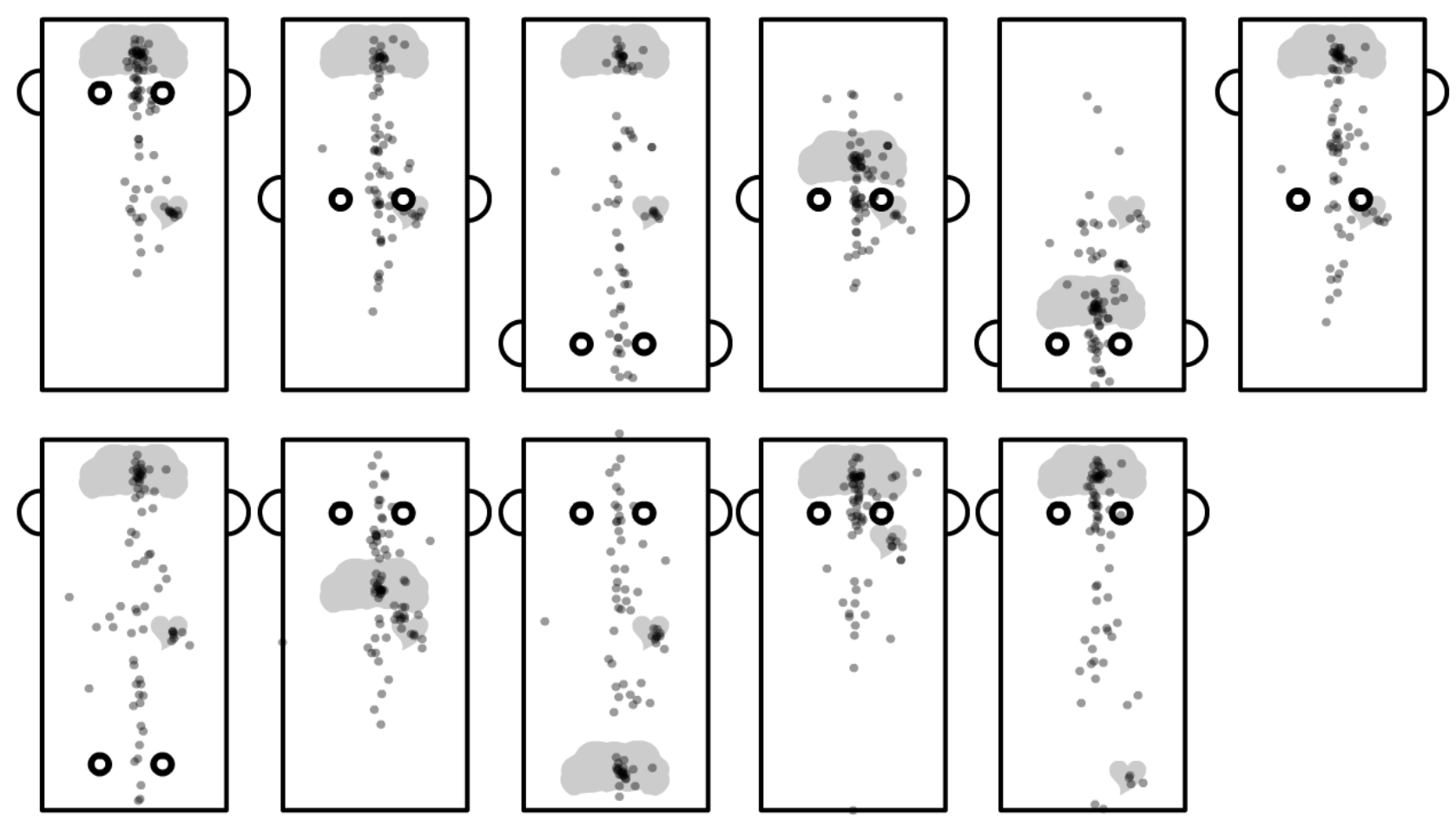

Figure 2.

Self-location judgment distributions of both conditions for each of the eleven rectangles. Each dot represents one participant's tag.

strongly and highly significantly with the vertical position of the SLJs, $r=.457 ; p<.001$. A small, but significant partial correlation was also found for the rectangles' eye-position and the SLJs, $r=.29 ; p<.001$.

Overall, participants agreed that there existed a single point in the human body (84.6\% "yes"), and also in the rectangles' body (65.4\% "yes") and also in the rectangles' body $(65.4 \%$ "yes"), at which subjective experience was strongest. The importance of the location of the brain for the location of this point of strongest subjective experience was emphasized by observers in both conditions (64.6\% "yes"; however, slightly more so in the Self than in the phenomenal Self condition, $F(1,64)=4.80, p<.032)$. The location of the heart $(40.9 \%$ "yes"), the sensory organs (51.5\% "yes"), and other variables (30.3\% "yes") were judged to be comparatively less important.

\section{Discussion}

First of all, we have to emphasize the fact that despite the demanding task, less than $17 \%$ of participants (a number not unusual for online experiments, see e.g. Hecht, Oesker, Kaiser, Civelek, \& Stecker, 1999) aborted or did not correctly complete the study, while all others showed a clear willingness to deal with the questions. Thus, $83 \%$ of volunteers who stumbled upon the questionnaire, which was advertized through a number of university websites, were both willing and able to follow the request to localize their Self.

The lack of any differences between the two conditions with and without prior definition of the phenomenal Self suggests that the notion of an egocenter came naturally to our partici- pants. It seems that participants did not distinguish between their Self and the center of subjective experience.

In the first part of the study, the distribution of participants' SLJs showed a division into two main clusters centered on the human brain and heart respectively-although these organs were not even displayed. Correspondingly, the brain and the heart were the two bodily organs most often specified by participants as being of importance for the location of the Self. The fact that participants could have opted to name a different part of the body or abstain from mentioning any part altogether suggests, again, that the task was meaningful to them.

The location of the Self on the rectangles (part 2) differed from the Self-location on the basis of the human silhouette (part 1) in an interesting way: whereas the location of the rectangles' Self did not show any significant relation to the position of the heart, it corresponded strongly to the position of the brain. Arguably, the task of locating a Self inside a box with human-like organs could have been perceived as nonsensical in itself. However, in the context of our study this is unlikely as it does provide some resolving power indicated by the clear differential effects for heart and brain.

Of course, the present study is exploratory in nature and the results have to be interpreted with great caution. The standard caveats that accompany the operationalization of a highly complex concept apply. For example, participants could have been unable to understand our definitions of the Self above and beyond the everyday language meaning of the concept. The notion of the Self may have remained opaque to our participants-however, not too opaque to prevent them from readily responding to our request of localizing the Self. It has to be noted that, when exploring subjective phenomena, we have to 
"trust" the subject (Jack \& Roepstorff, 2003; Dennett, 2003). Put differently, objective validity may be difficult to ensure. However, we believe that the study of first-person phenomena will always be confronted with this difficulty. We have shown that despite the validity problem, the question of locating the Self can be posed in a way that is meaningful and productive without challenging the subjectivity of experience.

We need not assume the existence of a true location of the Self in order to test empirically whether or not people are able to locate what they take to be their own Self. Our participants readily did so with a clear preference to locate the Self in the brain and in the heart. In the more abstract case of schematic placements of organs in a rectangle, the preference was entirely in favor of a spatial correspondence of Self and brain.

A spatial approach to the Self has many implications, and one has to be aware of its potential problems. A rich phenomenon like a Self-a person-does certainly not just "occupy space" (Adams, 1995). The Self and consciousness can be detached from a discrete physical location, they extend into space and time (Clark, 1999; Clark \& Chalmers, 1998). Still, life needs boundaries (Damasio, 1999), and the body constitutes such an elementary boundary. We "own" a body (Gallagher, 2000; Blanke \& Metzinger, 2008), and we experience our body and Self as unified at a single location in space (Lenggenhager, Mouthon, \& Blanke, 2009). Thus, a "geometrical viewpoint" (Adams, 1995) of the Self remains intuitive to us, as it seems to capture one of the fundamental conditions of being a Self: the first-person perspective (cf. Blanke \& Metzinger, 2008).

We take the results of this study to be an encouragement to further pursue the idea of Self-location. People readily provide a single point to correspond to their perceived Self. A point thus specified can be of great importance to current research on the location of the egocenter (see e.g. Sukemiya et al., 2008; Neelon et al., 2004), and may provide an important new basis for many unresolved research questions. It could be tested as an origin of the personal coordinate system described above (Roelofs, 1959; Albus, 1991; Metzger, 1941/2001; Merker, 2007; Bertossa et al., 2008). For example, the thus measured origin of personal space could help answer the question whether personal space is distorted, such that the resolution and detail of our phenomenal space increase the closer we get to its origin (Amir \& Kugelmass, 1959; Metzger, 1941).

A different, but equally important application of Self-location judgments could be in diagnosis and therapy of pathological and neurological conditions, where a quick and easy to administer self-report like the one used in this study could be a valuable addition to the diagnosis and treatment process. For example, the study of illusions like out-of-body experiences (cf. Lenggenhagar et al., 1999; Blanke \& Metzinger, 2008) could benefit from this method. In the same way, other possible questions could examine the constancy of this Self-location judgment as function of different cognitive states of agency, alertness, etc. (see Pikler, 1929, for a study on where the will attaches to the body). Lastly, it may be noted that regardless of our supposedly brain-centered world-view, in the present study the heart was essentially important to many participants. A large number of participants located their Self in the heart area-when the human silhouette was used as reference. Thus, it seems that the heart is still considered to be crucially important for the human Self.
The relationship between the body and the Self is a model example of a traditionally philosophical question, which recently has also sparked the interest of empirical science. But despite scientific and technical progress, when approaching a phenomenon like the perceived location of the Self, it is very important to include the subjectivity of experience into its analysis. Methods like the one presented in this studycombining a third-person approach with first-person self-reports - could be valuable to philosophers, clinicians, neurologists, and cognitive psychologists working on the interface between the mind and the body.

\section{Acknowledgements}

Jakub Limanowski would like to thank Shimon Edelman for inspiring discussions about the topic of this paper.

\section{References}

Adams, P. C. (1995). A reconsideration of personal boundaries in space-time. Annals of the Association of American Geographers, 85, 267-285. doi:10.1111/i.1467-8306.1995.tb01794.x

Albus, J. S. (1991). Outline for a theory of intelligence. IEEE Transactions on Systems, Man, and Cybernetics, 21, 473-509. doi:10.1109/21.97471

Amir, N., \& Kugelmass, S. (1959). The kinesthetic estimantion of distances in relation to midline of the body in normal persons. Acta Psychologica, 1959, 235-244. doi:10.1016/0001-6918(59)90097-6

Bertossa, F., Besa, M., Ferrari, R., \& Ferri, F. (2008). Point zero. A phenomenological inquiry into the subjective physical location of consciousness. Perceptual and Motor Skills, 107, 323-335.

Blanke, O., \& Metzinger, T. (2008). Full-body illusions and minimal phenomenal selfhood. Trends in Cognitive Sciences, 13, 7-13. doi:10.1016/j.tics.2008.10.003

Brewer, B. (1992). Self-location and agency. Mind, 101, 17-34. doi:10.1093/mind/101.401.17

Clark, A. (1999). An embodied cognitive science? Trends in Cognitive Sciences, 3, 345-351. doi:10.1016/S1364-6613(99)01361-3

Clark, A., \& Chalmers, D. J. (1998). The extended mind. Analysis, 58, 7-19. doi:10.1111/1467-8284.00096

Claparède, E. (1924). Note sur la localisation du moi. Archives de Psychologie, 19, 172-182.

Cutting, J. E. (1997). How the eye measures reality and virtual reality. Behavior Research Methods, Instrumentation, and Computers, 29 29-36.

Damasio, A. (1999). The feeling of what happens: Body, emotion and the making of consciousness. London: Vintage Books.

Dennett, D. (2003). Who's on first? Heterophenomenology explained. Journal of Consciousness Studies, Special Issue: Trusting the Subject? (Part 1), 10, 19-30.

Edelman, S. (2007). Computing the mind. Oxford: Oxford University Press.

Erkelens, C. J., \& Ee van, R. (2002). The role of the cyclopean eye in vision: Sometimes inappropriate, always irrelevant. Vision Research, 42, 1157-1163. doi:10.1016/S0042-6989(01)00280-2

Funaishi, S. (1926). Ueber das zentrum der sehrichtungen. v. Graefe's Arch. f. Ophthalm, 116, 126-134.

Gallagher, S. (2000). Philosophical conceptions of the self: Implications for cognitive science. Trends in Cognitive Sciences, 4, 14-21. doi:10.1016/S1364-6613(99)01417-5

Gallagher, S. (2005). How the body shapes the mind. Oxford: Clarendon Press.

Grossberg, S., Guenther, F., Bullock, D., \& Greve, D. (1993). Neural representations for sensory-motor control, II: Learning a head-centered visuomotor representation of 3-D target position. 
Neural Networks, 6, 43-67. doi:10.1016/S0893-6080(05)80072-3

Hecht, H., Oesker, M, Kaiser, A., Civelek, H., \& Stecker, T. (1999). A perception experiment with time-critical graphics animation on the World-Wide Web. Behavior Research Methods, Instruments, \& Computers, 31, 439-445. doi:10.3758/BF03200724

Hering, E. (1942). Spatial sense and movements of the eye. A. Raddle, Trans.). Baltimore, MD: American Academy of Optometry (Original work published 1879).

Hofmann, F. R. (1926). Ueber die Sehrichtungen. Graefe's Archive for Clinical and Experimental Ophthalmology, 116, 135-142. doi: 10.1007/BF01854226

Howard, I. P., \& Templeton, W. B. (1966). Human spatial orientation. New York: John Wiley and Sons, Inc.

Jack, A. I., \& Roepstorff, A. (2003). Why trust the subject? Journal of Consciousness Studies, 10, 5-24.

James, W. (1890). The principles of psychology. New York: Dover. doi:10.1037/11059-000

Lenggenhager, B., Mouthon, M., \& Blanke, O. (2009). Spatial aspects of bodily self-consciousness. Consciousness and Cognition, 18, 110-117. doi:10.1016/j.concog.2008.11.003

Mapp, A. P., \& Ono, H. (1999). Wondering about the wandering cyclopean eye. Vision Research, 39, 2381-2386. doi:10.1016/S0042-6989(98)00278-8

Merker, B. (2007). Consciousness without a cerebral cortex: A challenge for neuroscience and medicine. Behavioral and Brain Sciences 30, 63-81. doi:10.1017/S0140525X07000891

Merleau-Ponty, M. (1962). Phenomenology of perception (C. Smith, Trans.). London: Routledge \& Kegan Paul (original work published 1945).

Metzger, W. (1941/2001). Psychologie-entwicklung ihrer grundannahmen seit der einführung des experiments, 6. Auflage. Wien: Verlag Krammer.

Metzinger, T. (2004). The subjectivity of subjective experience: A representationalist analysis of the first-person perspective. Networks,
3-4, 33-64.

Nagel, T. (1971). What is it like to be a bat? The Philosophical Review, 83, 435-450. doi:10.2307/2183914

Neelon, M. F., Brungart, D. S., \& Simpson, B. D. (2004). The isoazimuthal perception of sounds across distance: A preliminary investigation into the location of the audio egocenter. The Journal of Neuroscience, 24, 7640-7647. doi:10.1523/JNEUROSCI.0737-04.2004

Ono, H., \& Angus, R. G. (1974). Adaptation to senory-motor conflict produced by the visual direction of the hand specified from the cyclopean eye. Journal of Experimental Psychology, 103, 1-9. doi: $10.1037 / \mathrm{h} 0036786$

Ono, H., Mapp, A. P., \& Howard, I. P. (2002). The cyclopean eye in vision: The new and old data continue to hit you right between the eyes. Vision Research, 42, 1307-1324. doi:10.1016/S0042-6989(01)00281-4

Pikler, J. (1929). Über die Angriffspunkte des willens am körper. Zeitschrift für Psychologie, 110, 288-291.

Roelofs, C. O. (1959). Considerations on the visual egocenter. Acta Psychologica, 16, 226-234. doi:10.1016/0001-6918(59)90096-4

Shimono, K., Higashiyama, A., Tam, W. J. (2001). Location of the egocenter in kinesthetic space. Journal of Experimental Psychology: Human Perception and Performance, 27, 848-861. doi:10.1037/0096-1523.27.4.848

Sommer, R. (2004). From personal space to cyberspace. Série: Textos de psicologia ambiental, No. 1. Brasilia, DF: UnB, Laboratório de Psicologia Ambiental.

Sukemiya, H., Nakamizo, S., \& Ono, H., (2008). Location of the auditory egocentre in the blind and normally sighted. Perception, 37, 1587-1595. doi: $10.1068 / \mathrm{p} 5949$

Helmholtz von, H. (1962). Helmholtz's treatise on physiological optics (J. P. C. Southall, Trans. and Ed.). New York, NY: Dover Publication (Original work published 1866). 